\title{
El cooperativismo mexicano, bajo el contexto de la Economía Social
}

\author{
Martha E. Izquierdo Muciño'
}

Recibido: $\quad 05.06 .10$

Aceptado: 20.06 .10

Sumario: Introducción. 1. Entre planificación y mercado. 2. Una economía alternativa. 3. Evolución histórica del concepto de Economía Social. 4. Principales actores del concepto de Economía Social. 5. Políticas Públicas del concepto de Economía Social. 6. Cooperativismo mexicano. Bibliografía.

Resumen: El cooperativismo es un sistema que se diferencia de los demás por su muy peculiar naturaleza valorativa y por su forma especial de satisfacer las necesidades individuales y colectivas, constituyendo un sistema alternativo al actual modelo neoliberal que puede coadyuvar a eliminar la injusticia social y a reducir los niveles de pobreza, de tal suerte que sería un error cambiar el espíritu de ayuda mutua por el de lucro personal de las actividades económicas.

Palabras clave: Empresas cooperativas, naturaleza especial y problemas de las cooperativas mexicanas.

Abstract: The cooperativism is a system that differs from the others for his very peculiar nature to value and for his special way of satisfying the individual and collective needs, constituting an alternative system to the current neoliberal model who can contribute to eliminating the social injustice and to reducing the levels of poverty, of such luck that would be a mistake to change the spirit of mutual help for the personal profit of the economic activities.

Key words: Cooperative companies, special nature and problems of the mexican cooperatives.

1 Doctora en Derecho (UNAM), Catedrática e Investigadora de la Universidad Autónoma del Estado de México (UAEM), adscrita al Sistema Nacional de Investigadores (SNI), con publicaciones sobre temas de Derechos Humanos, Derecho Social y Derecho Internacional para la Paz. 


\section{Introducción}

La crisis generalizada de los países latinoamericanos, ha vuelto a poner en boga nuevamente la alternativa cooperativista y autogestionaria, en medio de la desesperación social, del hundimiento de la productividad, las altas tasas de desempleo y la marginalidad de nuestras sociedades, lo cual nos obliga a reflexionar acerca de una alternativa más viable, más justa y más humana.

Esta crisis generalizada nos hace voltear los ojos hacia la creación de empresas cooperativas y autogestionarias como alternativas de solución a los problemas aquí planteados, ante la desesperación de miles de mexicanos y ante el resquebrajamiento paulatino de las estructuras social y económica, pero lo más grave ha sido la desigualdad social que nos lleva a tener hoy día a una tercera parte de mexicanos en la pobreza extrema.

Los grupos cooperativos, comunitarios y autogestionarios en América Latina, así como otras formas societarias de carácter autogestionario intentan constituir un tercer sector de la economía, capaz de competir con los sectores estatal y capitalista.

En efecto, a pesar de la diversidad de alternativas existentes, la Economía Social y solidaria es hoy una realidad, ha encontrado y encuentra obstáculos para su efectiva instrumentación y desarrollo pero contiene dinamismos propios y concretizadores en todo el mundo que la hacen confiable como propuesta de cambio en relación del hombre con su entorno productivo y del hombre con el hombre.

Sea que la Economía Social y solidaria se materialice en empresas cooperativas genuinas de gran envergadura o en formas incipientes de participación social o familiar, es sin duda un modelo que desafía concretamente a las formas individualistas y capitalistas de producción y distribución de bienes servicios y crédito. El carácter solidario de éste modo, está dado por su humanismo intrínseco, comprometiendo la misma administración de las empresas.

Por lo anterior consideramos que al potenciar el desarrollo cooperativista mexicano y sistemas de autogestión, se podrá promover la participación de los sectores populares en la creación de un estilo de desarrollo de naturaleza alternativa al prevaleciente.

La figura del cooperativismo contiene en si misma valores y principios éticos que la hacen distinta de las demás empresas toda vez que las finalidades que persigue son totalmente diferentes. Estos principios en el año de 1995 fueron reiterados por la Alianza Cooperativa internacional en un congreso celebrado por motivo de sus cincuenta años de existencia. 
Por otra parte puede asegurarse que en nuestro país existe desde hace muchos años un sector social de la economía que se identifica plenamente con el rubro de las cooperativas, lo que la hace todavía más interesante, pues no debemos olvidar que la sociedad debe esforzarse por detectar las necesidades en su entorno y contribuir con respuestas y servicios para la solución de los problemas, asimismo vale la pena desarrollar investigación y generar conocimientos que por un lado contribuyan a reducir las marcadas desigualdades entre los habitantes de la entidad y por otro enriquezcan la aplicación del saber nacional y universal.

\section{Entre planificación y mercado}

La globalización es el proceso por medio del cual los habitantes del mundo, tienen una mayor interrelación en todos las facetas de la vida: culturales, económicas, políticas, tecnológicas y del entorno, sin embargo algo que se observa es que el crecimiento económico cuando esta fundado sobre las bases de un capitalismo globalizado conduce forzosa y necesariamente a la concentración del capital, lo cual genera miseria.

En nuestro país (México), se observa que a casi 14 años de la firma del tratado de libre comercio (TIC) el cual quedó fundado sobre el capital global, nos ha conducido a una gran concentración del capital a grado tal que en la actualidad contamos con mas de la mitad de mexicanos en la pobreza y a una tercera parte en pobreza extrema².

Este fenómeno se observa en las cuatro quintas partes del planeta de la actual era de la globalización. Al respecto Víctor Flores Olea comenta:

El capitalismo otorga la gloria a algunos pocos mientras que las mayorías quedan marginados de sus beneficios. ${ }^{3}$

Por otra parte existe el informe sobre Desarrollo Humano de 1992 que fue un programa de Naciones Unidas para el desarrollo, en el que se contempla desde aquel tiempo que el $20 \%$ de la humanidad con mayores ingresos recibía el $82.7 \%$ del producto mundial y que en cambio el $20 \%$ situado en la pobreza extrema apenas recibía $1.4 \%$ de ese producto, por tanto el producto combinado del $20 \%$ más rico sería

2 Delgado, Orlando, «Discurso y realidades», periódico La Jornada, 7 de dic., 001

3 Flores Olea, Víctor, Crítica de la globalidad, México, Fondo de Cultura Económica, 2000, p. 288. 
6 veces más grande que el de los más pobres, ${ }^{4}$ Con lo cual se infiere que es dramáticamente extrema la diferencia que existía entre ambos ingresos, creándose con ello un abismo infranqueable (150 veces entre ambos ingresos.)

Esta división entre países ricos y pobres se ve reflejada en las clases sociales actualmente, esto es: entre propietarios y no propietarios sin importar el país al que pertenezcan.

De tal suerte que la mundialización o globalización de la economía al ser una realidad irreversible según comenta Flores Olea, determinará la prosperidad y el provecho que de ella se puede lograr, de las relaciones que cada país pueda obtener de ella, de la dirección que se le imprima y de los objetivos que se alcancen, esto es que:

Oponerse a la mundialización no sólo es una ingenuidad sino que significa rechazar el horizonte de riquezas abierto por la universalización de las relaciones humanas ${ }^{5}$.

Sin embargo se observa que la mundialización al estar condicionada por la lógica del capitalismo tiene efectos perversos, pues se genera división del trabajo de acuerdo a los intereses de las grandes corporaciones, contraponiéndose a la satisfacción de las necesidades sociales mas urgentes en cada país, ocasionando con ello disgregación y enfrentamientos en todo el mundo, por tanto para que para que las fuerzas de la economía y la tecnología se realicen positivamente, confiriéndole al individuo la posibilidad de superar sus limitaciones materiales y de todo tipo, es necesario aprovechar la mundialización, siempre y cuando se rescaten los valores del trabajo, de la sociedad y de la cooperación, toda vez que esto sería un freno a la voracidad del capitalismo mundial para controlar sus excesos, pues como comenta el citado autor:

El rescate de la mundialización para fines sociales y humanos, se hace más urgente que nunca...6.

Se hace hincapié en que la única forma de eliminar los fundamentos objetivos de la especulación es acabando con las condiciones de sobre acumulación generalizada del capital productivo, con lo que se daría un gran salto en la dinámica general de la productividad social del trabajo.

\footnotetext{
4 Cfr.

5 Ibidem, p. 285.

6 Ibidem, p. 293.
} 
Por su parte Joan Ginebra comenta que es necesario defender la libre iniciativa frente a la burocracia y los controles innecesarios, defender la libre iniciativa de las acciones monopólicos que la combaten (sean del Gobierno o privadas)». ${ }^{7}$ Como pude observarse la discusión central gira en torno al papel del mercado por un lado y de la planificación estatal por el otro, ambas son posiciones extremas, pues por un lado se reconoce que el mercado ha sido históricamente eficaz para estimular la tecnología y algunos cambios progresistas incluyendo los aspectos político y social, pero en todas estas innovaciones ha estado también la mano del Estado, por otro lado se denota el fracaso del mercado como mecanismo para mejorar los niveles de vida.

La planificación central por su parte ha demostrado capacidad para obtener mas o menos satisfacción generalizada de las necesidades básicas como la alimentación, la salud, educación y vivienda pero a costa del sacrificio de las libertades individuales y políticas del individuo, por lo anterior surgen las siguientes preguntas: ¿es posible la explotación del mercado sin la explotación capitalista?, ¿es posible una nueva economía alternativa que se base en la cooperación y en la ganancia? Si la respuesta es si, entonces la pregunta será: ¿se esta hablando de un socialismo de mercado con énfasis en una sociedad socialista?, si la respuesta es no, significa que el desarrollo del socialismo sería incompatible con el mercado. ${ }^{8}$

Frente a la disyuntiva entre planificación y mercado se debe enfatizar que la única forma para el desarrollo de las libertades individuales y con ello el de toda la sociedad radica en la «autoorganización» y en la «autogestión» comunitaria entre los individuos que la conforman, eliminando con ello la preeminencia tanto del estado como del mercado y debiendo prevalecer el principio de la solidaridad, pues la historia ha demostrado que con el mercado se anula la posibilidad de satisfacer las necesidades colectivas e individuales y con la concentración del poder del Estado se liquida la libertad del individuo y de la sociedad. ${ }^{9}$

En consecuencia se observa que lo que esta surgiendo ahora es una confrontación cada vez más enconada entre esos órganos y los organismos estatales, de igual forma con las agrupaciones políticas tradicionales.

Se observa por tanto que al igual que la sociedad civil, las agrupaciones cívicas tienden a sustituir los poderes centralizados del Estado, con-

7 Ginebra Joan, La Trampa Global, 2. ${ }^{\text {a }}$ reimp., México, Panorama, 1999, p. 56.

8 lodqe, George, C. Administrando la globalización en la era de la independencia, trad. de: Juan Carlos Jolly, México, Panorama, 1966, p. 137.

9 Flores, Víctor, op. cit., nota 2, p. 238. 
virtiéndose en nuevos centros de poder, en todo caso se hace imprescindible avanzar en el desarrollo de las condiciones que hagan posible el éxito de las asociaciones directas y libres (autogestionarias) de la sociedad civil, como base de la organización alternativa de las naciones ${ }^{10}$.

\section{Una economia alternativa}

A lo largo de las dos ultimas décadas, ha existido en todo el mundo un desenvolvimiento de innumerables formas de organización económica que se han caracterizado como economías alternativas, los cuales resultan ser distintas a las que operan bajo patrones clásicos de le economía capitalista privada y la economía estatal regulada.

En muchos países estas formas han sido catalogadas como pertenecientes a un «tercer sector de la economía» otros prefieren hablar de «Economía Social», «Economía popular» y hasta de «Economía Solidaria».

Ahora bien, ¿qué son las economías alternativas? Una primera respuesta surge de los diversos sectores sociales que promueven este tipo de organización, entendiéndola en relación a las lógicas de valores que caracterizan el comportamiento mercantil, de esta manera se parte de la idea de que "el mercado es cruel», que formula desigualdad y acaparamiento en unas cuantas manos. ${ }^{11}$

Otra respuesta de carácter socioeconómico determina que siendo el mercado un producto social puede ser realmente constructivo desde el punto de vista de "Mercado determinado», el cual se entiende como aquel que se constituye con todas las lógicas existentes en la sociedad, con todos los valores, todos los flujos, todas las relaciones, etc. por lo cual viéndolo de esta perspectiva deja de ser meramente capitalista. ${ }^{12}$

En dicho contexto operan fuerzas capitalistas pero también fuerzas estatales, las pertenecientes al tercer sector que a su vez albergan en su interior diversas formas de hacer economía, y bajo este concepto es excesivo aceptar que. «El mercado es cruel»

En el Sector Social tienen lugar las relaciones de carácter integrativo como son:

10 ldem.

11 Colomer, Antonio (coord.), Sociedad Solidaria y desarrollo alternativo, Madrid, Fondo de Cultura Económica, 1993, p. 263.

12 Guerra Pablo, S., "Análisis socioeconómico de las economías alternativas», Revista Iberoamericana de autogestión comunal, Universidad de Valencia, España, núm. 34, Segunda Época, otoño de 1999, p. 63. 
- Relaciones de cooperación: (En la que diversos sujetos aportan en común y reciben de acuerdo con dicho aporte como sucede en las cooperativas).

— Relaciones de Comensalidad: (Donde algunos sujetos aportan y luego se redistribuye de acuerdo a las necesidades de cada integrante del grupo, como sucede en las comunidades, en las familias, etc.).

- Relaciones de reciprocidad: donde se aporta sin esperar a cambio ningún aporte de igual valor como en las relaciones de vecindad.

— Relaciones de donación: estudiada y analizada como acto de gratuidad, trabajo voluntario, etc.

Todas estas expresiones exportan su cuota de Solidaridad a los mercados determinados.

Algunos trabajos sobre el tercer sector sobre todo en Norteamérica hacen hincapié en este: "nuevo fenómeno» que implica un manejo de millones de dólares en todo el mundo, así como energía, trabajo y voluntad de miles de personas que destinan parte de su tiempo y dinero a causas que no son atendidas por las relaciones de intercambio. ${ }^{13}$

Pero qué es la economía alternativa?, ¿Cómo podríamos conceptuarla?, la entendemos como Economía Social ó Sector Social?, pues bien esta actividad se refiere a campos del quehacer económico y de la organización social aún insuficientemente definida, pero una aproximación sería aquella que definiera al sector social por exclusión, dado que no se trata de empresas privadas, tampoco de empresas del Estado y por agregación sería aquella que definiera al sector social por exclusión, dado que no se trata de empresas privadas, sino de empresas cooperativas y sindicales, propiedad comunal, ejido, unidades de producción familiares y autoempleo, no siempre existe consenso al respecto, por lo que parecería conveniente agregar etc. etc.

Luego entonces como sector social podemos entender a las formas de organización de producción "atípica», pero por un lado se encuentran empresas formales de propiedad colectiva pero por otra parte existe una gran gama de informalidad y de marginación con múltiples mecanismos por la supervivencia basada en los lazos familiares y colectivos. ${ }^{14}$

El propio "capitalismo salvaje» en ocasiones se encuentra disfrazado de alguna de las formas anteriores, esto es empresas que operan

13 Idem.

14 J. Franco, La construcción del sector social, http//www.spin.com.mx/franco/ pobreza/social.html. 
en clandestinidad para evadir impuestos, aspectos legales y sobre todo laborales.

Al sector social nos aproximamos si lo identificamos como un ámbito de capacidades productivas, bajo el control de esta definición global (aunque insuficiente) pudiendo plantearse algún concepto convencional sobre el sector social, para pasar a un enfoque propositivo, entendiéndola como: el diseño estratégico y operativo de la conformación de un sector social fuerte, con posibilidades de desarrollo auto sustentado en el contexto de la economía y de la sociedad.

Cabe destacar que desde diversas vertientes se denota la impaciencia de algunos sectores de la sociedad por la necesidad de que sean atendidas sus reclamos, ya sea definiendo líneas de estrategia económica (que pretenden atenuar las fusiones sociales). En este sentido parecen abrirse opciones de impulso al sector social cuyo alcance va en la medida de la evolución de los sectores modernos de la economía. ${ }^{15}$

En México se observa que este impulso a las formas de producción «atípicas» se ha dado en los periodos de estancamiento de la economía formal, respondiendo con ello a la búsqueda de alternativas de los sectores mas afectados.

Como ejemplo podemos citar el gran impulso que se dio al ejido en los años «30», lo cual respondía a una situación de estancamiento económico y al retorno de miles de Mexicanos de los Estado Unidos producto de la crisis en 1929. ${ }^{16}$

El impulso al cooperativismo, al ejido, y a las sociedades de solidaridad social se dio a raíz de la crisis agrícola gestada a partir de 1966, que trajo consigo medidas de corte populista.

Por el contrario en épocas de crecimiento económico, se cita entre ellas: «la recuperación de la posguerra», «el desarrollo estabilizador», o «la administración de la abundancia», no se observan estos impulsos.

En la actualidad los países llamados del tercer mundo (como el nuestro) han saturado los mercados centrados de productos convencionales a costa de la desintegración de sus economías y de sentido del consumo de los sectores populares, los países industrializados en cambio han seguido una política de integración productiva de mercados periféricos para su producción teniendo como resultado un grave deterioro de la relación de intercambio centro-periferia, en detrimento de la mayoría de las naciones y de la población del planeta.

15 Cooperativas en Centroamérica, IV Conferencia de la Federación de Universidades de América Central y Panamá, Guatemala, FUPAC ediciones, 1979, p. 37.

16 Franco, ob. cit., nota 20, p. 3. 
Por lo anterior podemos afirmar que la crisis va conduciendo a una paralización progresiva de la capacidad de producción periférica, esto significa que van perdiendo su propio mercado el cual se encuentra invadido por la producción central, dando lugar a una reorientación de la producción a favor del mercado de consumo en las clases medias y altas del planeta, que es en donde se ubica la capacidad de demanda observándose que este fenómeno produce a la vez una situación de competencia excesiva. ${ }^{17}$

Como resultado de estas acciones se da la desintegración interna de las economías periféricas contra la integración y fortalecimiento internacional de los sectores mas modernizados, provocando graves problemas para la población del planeta en términos de eficiencia productiva, empleo, consumo y autodeterminación. Joseph E. Stiglitz, premio Nóbel de Economía 2001 menciona:

...hay bastante más participación de los países en desarrollo en las discusiones sobre su estrategia económica, pero la evidencia sobre cambios en las políticas que reflejen una mayor participación aun es escasa, tienen que cambiar las instituciones y los esquemas mentales. La ideología del libre mercado debe ser reemplazada por análisis basados en la ciencia económica, con una visión mas equilibrada del poder del Estado, a partir de una comprensión de las fallas tanto del mercado como del Estado.

Esto es, que debe existir mayor sensibilidad sobre el papel que jueguen los asesores externos, de tal modo que respalden la toma democrática de decisiones clarificando las consecuencias de las distintas políticas, incluyendo los impactos sobre los diferentes grupos sociales, en especial los paises pobres» ${ }^{18}$ y la pregunta que surge es: ¿Con qué estrategias de desarrollo puede vivir la población que le permita crecer y tener una respuesta a las amplias necesidades del tercer sector de la economía?

Un elemento primordial del sector social serìa la propiedad colectiva en la empresa pero en estas necesidades como en cualquier otra se habla de una necesidad de adaptarse "Competitivamente» a los mercados, so pena de conductismo hacia el fracaso.

La condición de empresa de propiedad social brinda ventajas relevantes en términos de productividad, pues se tiende a relegar los seg-

17 Ídem.

18 Stiglitz, Joseph E. «El malestar de la globalización», Editorial Taurus, México 2000. p. 273. 
mentos de la actividad económica que no son de interés de la empresa privada dada su baja rentabilidad.

El sector social luego entonces debe estar orientado a cubrir esos aspectos «descuidados», como la producción para el consumo popular o la creación de empleos.

\section{Evolución histórica del concepto de Economía Social}

La Economía Social (ES) aparece por primera vez en Europa, vinculada históricamente a las asociaciones populares y cooperativas que constituyen fundamentalmente su eje vertebrador.

De hecho puede afirmarse que el sistema de valores y los principios del asociacionismo popular sintetizados por el cooperativismo histórico son los que han servido para articular el moderno concepto de ES, que gira en torno a tres grandes familias de organizaciones; cooperativas, mutualidades y asociaciones y en últimas fechas se incorporan las fundaciones.

Estas familias constituyen en su origen histórico, manifestaciones de respuesta de los grupos sociales más indefensos y desprotegidos mediante organizaciones de autoayuda; ante las condiciones de vida generadas por el capitalismo industrial de los siglos XVIII y XIX.

No obstante a lo largo de la Edad Media surgieron organizaciones de caridad como fundaciones de beneficencia, cofradías, hospitales y de socorros mutuos, etc. Lo cierto es que es en el siglo XIX cuando el asociacionismo popular, el cooperativismo y el mutualismo conocen un auténtico impulso de las clases trabajadoras. ${ }^{19}$

El termino «Economía Social» aparece por primera vez en 1830, el economista liberal francés Charles Dunoyer quien publicó en esta fecha un traité d'economie sociale, en donde propugnaba por un enfoque moral de la economía. De hecho fue en Francia en el periodo de 18201860 donde se desarrolló una corriente de pensamiento que puede denominarse de economistas sociales, influenciados en su mayoría por las teorías de Malthus y de S. de Sismondi.

Desarrollaron un enfoque teórico de lo social y de la sociedad, persiguiendo la reconciliación de la moral y de la economía a través de la moralización de las conductas individuales que pretendían la paz social.

Posteriormente en la segunda mitad del siglo XIX la Economía Social conoce una profunda reorientación bajo el impulso de Stuart Mill y León Walras.

19 Chávez Rafael y Monzón José Luis. La Economía Social en la Unión Europea. Comité Económico y Social Europeo, 2009, p. 13. 
J.S. Mill dedicó una gran atención al asociacionismo empresarial de los trabajadores, tanto en su vertiente cooperativa como mutualista. En su obra " principios de economía política, analizó con detalle las ventajas e inconvenientes los detalles de las cooperativas de trabajadores, pugnando por el fomento de este tipo de empresas, en virtud de sus ventajas económicas y sociales.

Por su parte León Walras al igual J.S. Mill, consideró que las cooperativas podían desempeñar una relevante función en I solución de conflictos sociales, cumpliendo un gran papel económico que consistía en :

no suprimir al capital sino luchar por que el mundo sea menos capitalista y en introducir la democracia en el mecanismo de la producción ${ }^{20}$.

Su obra Estudios de Economía Social fue publicada en Lausana en 1896 y trajo consigo una importante reflexión de forma diferente al enfoque primitivo de la Economía Social, en este sentido la Economía Social pasa a ser parte de la ciencia económica en la que se estudian a las cooperativas, las mutualidades y las asociaciones tal como actualmente se conocen.

Posteriormente en el siglo XIX se vinieron a perfeccionar las principales características del moderno concepto de Economía Social, el cual se inspiro en valores de asociacionismo democrático, de mutualismo y desde luego de cooperativismo.

Por otra parte puede mencionarse que la denominación y el concepto de Economía Social tal como se entienden en Europa no responden al sentir mayoritario en otros países como Ibero América, puesto que los términos Economía Solidaria o Tercer Sector son más aceptados y generalmente referidos al cooperativismo.

Lo cierto es que la Economía Social está dejando claro que promueve un desarrollo equitativo, humanizado, carente de agresividad y eso molesta.

Molesta a quienes han practicado un empresariado feroz y excluyente, carente de los principios éticos más simples y esenciales. De los que creen en la explotación y en las prácticas tramposas para ganar dinero, con resultados egoístas.

Luego nos enfrentamos a una primera dificultad respecto al término de Economía Social (ES). En América latina a la que también se le denomina economía solidaria o de la solidaridad desde hace varias décadas empieza a extenderse, viene a popularizarse desde media-

20 Ob. cit., p. 16. 
dos de los años 70's desde un punto de vista contemporáneo y económico-social pues es en América en donde se viven los rigores de las crisis económicas del petróleo dentro de un modelo neo liberal y la recesión económica internacional de los años 80's que refleja un ciclo de regímenes autoritarios con altos niveles de exclusión y represión social. ${ }^{21}$

En este contexto en el que se extiende el uso del concepto «Economía Solidaria», principalmente por los esfuerzos de la cooperación internacional no gubernamental que se traduce como aquella que no fluye a través de los gobiernos sino de las ONG y otros autores sociales como Sindicatos, Organizaciones de base.

Los principales exponentes desde el punto de vista intelectual y académico son: el Chileno Luis Razeto, Paul Singer (Brasil), Palilo Buerna (Uruguay), etc.

En Brasil la administración del gobierno encabezada por Luis Ignacio Lula da Silva ha creado en el contexto del Ministerio del trabajo una Secretaria de Estado en Economía Solidaria a cargo de la cual ha estado ya por varios años el profesor Paul Singer.

En Colombia el antiguo Departamento Nacional de Cooperativa DANCOOP, ha pasado a llamarse desde fines de los 90's Departamento Nacional de Economía Solidaria DANSOCIAL, ahora dependiente del Presidente de la República.

En Argentina, Uruguay y en Chile también ha ido cobrando fuerza este concepto.

Otro concepto que se ha extendido al respecto en los últimos años es el «Tercer Sector» que pone en énfasis que en la idea de que la organización económico-social de los países y de las sociedades se organiza en torno a tres sectores de la economía: publica, privada y aquel que reúne a todas las otras formas de empresa y organizaciones que se caracterizan porque no tienen fines de lucro y por la generación de bienes y servicios de interés público.

A la par de los anteriores términos se encuentra extendido el concepto de «Sector de Economía Social» el cual es todavía anterior a los ya citados, ya que se registra su uso en la mitad del siglo XIX en Francia.

En general todos ellos coinciden al afirmar que sus principios o estímulos son:

— Primacía de la reforma y del objeto social sobre el capital.

- Control democrático de sus miembros.

21 Rodrigàn Mario (coordinador), La Economía Social en Ibero América, vol. 3 FUNDIBES, Valencia, 2008, p. 16. 
- Conjunción de los intereses de los miembros o usuarios y del interés general.

- Defensa y aplicación de los principios de la solidaridad y responsabilidad.

- Autonomía de gestión e independencia respecto de los poderes públicos. ${ }^{22}$

Dentro de la mayoría de los excedentes a la consecución de los adjetivos a favor del desarrollo sostenible, del interés de los servicios a los miembros y del interés general.

Para conceptuar al Sector Social pueden encontrarse algunos otros términos como Economía Popular, economía alternativa, economía de interés general, sociedad civil, sector sin fines de lucro, economía de pobres etc.

La economía solidaria en México se define como: «...aquel conjunto de organizaciones que fundamentan su racionalidad económica y sus lógicas operaciones en la autogestión y la participación democrática de las comunidades productivas y sociales en las cuales se privilegian los objetivos y las expectativas de la comunidad y el trabajo como factores organizadores de la economía empresarial.»23

Se proyecta como una constructora del tejido social, capaz de regenerar las relaciones sociales hacia una economía más justa y pluralista, en donde coexistan; Estado, iniciativa privada y trabajo solidario.

Se plantea también como un mecanismo del desarrollo alternativo, capaz de construir nuevas propuestas al quehacer económico y social en el campo de la autogestión democrática. De hecho la economía Social y Solidaria en América, nace como una reacción a la exclusión social ó económica de todos los beneficios básicos para la vida, por eso esta reacción puede considerarse ante todo como una actitud defensiva.

Dicha reacción no surge en forma individual sino que se da en forma colectiva, puesto que la Economía Social es siempre colectiva, es la forma en que el hombre se agrupa con los demás hombres para integrarse al esquema económico del que se siente excluido, reaccionando con los «otros», de forma igualitaria. Así el proyecto que llegue a construir incluye una responsabilidad compartida al igual que los beneficios que se obtengan, por eso a estas organizaciones se les llama también «sociedad de personas».

22 Ob. cit., p. 19.

23 Cadena Barquín, Félix, De la economía popular a la economía de solidaridad. Mèxico. edita: El Colegio de Tlaxcala, FOMIX, ECOSOL, SEPUEDE, 2005, p. 26. 
Por tanto puede afirmarse que es en este entorno en donde aparece la realización de la "utopía» al hablar de solidaridad, que se concreta necesariamente en una realidad compartida y en un esfuerzo común, ya sea en la construcción de una vivienda, en la construcción de una pequeña empresa etc. Siempre y cuando dicha «utopía» mida sus posibilidades y su viabilidad toda vez que esto denota una realidad económica distinta, esto es: denota una alternativa económica. ${ }^{24}$

La Economía Social en América se utiliza para neutralizar lo que siente como amenaza o exclusión, creando riqueza y compitiendo con el mercado pero de una manera alternativa. Su base económica son los ahorros de las personas generalmente hecho a base de esfuerzos, lo cual exige mayor transparencia y eficacia.

Pero el ingrediente que da mayor cohesión es: "la solidaridad», siendo tan fuerte este concepto que bien podría afirmarse es el motor de la Economía Social para la creación de empresas colectivas, siempre y cuando estas sean creadas para el beneficio de todos sus integrantes, de forma igualitaria repercutiendo en el entorno social en forma de generación de empleo.

En México como en otros países existen diversos grupos en los que participan activistas sociales, académicos, líderes, funcionarios de gobierno, en aras de generar acciones a través de espacios de reflexión y discusión colectiva con el propósito de poder consensuar un marco conceptual acerca de la economía alternativa, como: Pablo González Casanova, José Luís Calva, Julio Boltuinik, Félix Cadena Barquín, Juan José Rojas, entre otros más, y en América Latina esta acción se ve coordinada por José Luís Coraggio (de Argentina), Francisco Gutiérrez (de Costa Rica), Luís Razeto (de Chile), Euclides Mance (Brasil), entre otros más. Participan también en torno a la disensión de la economía solidaria Francia y España. ${ }^{25}$

En el mes de noviembre del 2002 se llevó a cabo en la Ciudad de México el Foro Internacional de la Economía Social y Solidaria, organizado por la Secretaría de Economía a través de la Coordinación general del Programa Nacional de Apoyo para las Empresas de Solidaridad (FONAES).

Dicho foro contó con la participación de 400 personas y estuvo orientado al intercambio y análisis de ideas y experiencias sobre la Economía Social y Solidaria, tanto a nivel nacional como internacional de diversos sectores del gobierno y la sociedad.

24 CASTRO Sans, Marcos de, La Economía Social y solidaria, un proyecto complementario e incluyente, Foro Internacional de Economía Social y Solidaria (memoria), Secretaría de Economía , Comisión de Fomento Cooperativo y Economía Social, FONAES. México, 2002, p. 37.

25 Cadena, op. cit., p. 13. 
Se contó con distinguidas personalidades como:

- Denis Bussières. Coordinador de Economía Social en la Alianza para la Investigación Universidades-Comunidades de Canadá.

- Marcos de Castro Sánz, Presidente de la Confederación Empresarial Española de la Economía Social (CEPES) de España.

- Jaques Attali , presidente del PlaNet Finance de Francia

- Luis Razeto Migliaro, Vicepresidente de la Junta Directiva de la Universidad Boliviana de Chile

- Mario B. Monroy Gómez, Presidente de Comercio Justo A.C. de México.

- Ramón Imperial Zúñiga, Presidente del Consejo Mexicano de Ahorro y Crédito Popular.

- Jesús María Herrásti Erlogorri, Presidente de Mondragón ,Corporación Cooperativa (MCC) de España

- Lorenzo Servitje Sendra, Presidente del grupo Industrial Bimbo S.A.de C.V.de México.

- Manuel Mariño, Director General de la Alianza Cooperativa Internacional para las Américas.

- Martha T. Duràn Trujillo ,Presidenta de la Junta del Fondo de Garantías de Entidades Cooperativas (FOGACOOP) de Colombia, entre otros mas.

De entre las muchas aportaciones que se vertieron, destaca el reconocimiento de que la Economía Social permite a los hombres y a las mujeres así como a las colectividades desarrollarse y responder a sus propias necesidades, integrando los valores de la solidaridad y la justicia social, a través de nuevos empleos y nuevas formas de organización.

Asimismo que permite a todos aquellos que construyen la Economía social participar colectivamente en la posibilidad de hacer de otra forma la economía, permitiendo con ello romper el fatalismo en el que la ideología neoliberal nos encierra, pretendiendo ser el único modelo de desarrollo.

Las prácticas de la Economía Social permiten imaginar otras estrategias mas amplias y completas para desarrollar una economía mundial, global y solidaria. ${ }^{26}$

La necesidad de contar con tecnología simple, fácil y barata para los usuarios. Lograr una generación masiva de empleos y de recursos hacia

26 Foro Internacional de Economía Social y Solidaria, Secretaria de Economía, Comisión de fomento Cooperativo y Economía Social LVIII Legislatura de la Cámara de Diputados y Fondo Nacional de Empresas de solidaridad ( FONAES), México 2002 .p 26 
las distintas regiones que así lo requieran. Integrar cadenas comerciales de manera más competitiva y que en lugar de inventar mercados nuevos se utilicen los tres niveles de empresa que ya existen como son:

\author{
LA EMPRESA FAMILIAR MICRO, \\ LAS EMPRESAS COOPERATIVAS Y \\ LA UNIONES DE COOPERATIVAS O EMPRESAS DE MAYOR EN- \\ VERGADURA
}

\title{
4. Principales actores de la Economía Social
}

La Economía Social aun cuando no es un sistema institucionalizado y rígido para cada país, esta constituido por una gran variedad de tipos de entidades que responden mas bien a la historia vivida por cada país, así como a sus procesos sociales, económicos y políticos.

Sin embargo y más allá de la diversidad propia de cada país, en lo fundamental el sector de Economía Social esta básicamente constituido por:

1. Cooperativas. Que en la mayor parte de los países tienen un rol central, tanto por su número de entidades como de socios, a la vez que por su trayectoria histórica.

2. Mutuales.

3. Fundaciones sin fines de lucro.

4. Asociaciones con finalidad socio-productiva.

Para el Sector Social de la Economía (SSE) en México el propio artículo 25 Constitucional enumera algunas figuras asociativas que forman parte del SSE:

\section{Art. 25.}

...la ley establecerá los mecanismos que faciliten la organización y la expansión de la actividad económica del sector social: de los ejidos, organizaciones de trabajadores, cooperativas, comunidades, empresas que pertenezcan mayoritaria o exclusivamente a los trabajadores...

sobre esta base, diversas leyes de carácter particular, definen de forma más precisa las diferentes figuras asociativas que forman parte del SSE. Entre dichas leyes destacan principalmente las siguientes:

- La Ley Agraria, publicada en el Diario Oficial de la Federación (DOF) el 26 de febrero de 1992, regula el Ejido y a la Comunidad así como a las diferentes organizaciones productivas que se pueden crear al interior de dichos núcleos agrarios básicos, ellas son los sectores de producción, la Unidad Agrícola Industrial para la Mujer 
(UAIM), la Unidad Productiva para el Desarrollo Integral de la Juventud, las Empresas Ejidales especializadas, la Parcela Escolar v la Sociedad de Producción Rural (SPR). De igual manera, la Ley Agraria, regula los siguientes organismos de segundo y tercer grado: la Unión de Sociedades de producción Rural, la Unión de Ejidos y/o Comunidades y a la Asociación Rural de Interés Colectivo (ARIC).

- La Ley de Sociedades de Solidaridad Social, publicada en el DOF el 26 de mayo de 1976, se encarga de regular a la Sociedad, a la Federación y a la Confederación de Sociedades de Solidaridad Social (SSS).

- Por su parte la Ley General de Sociedades Cooperativas (LGSC), publicada en el DOF el 3 de agosto de 1994, regula a la Sociedad, a la Unión, a la Federación y a la Confederación de Sociedades Cooperativas.

- Por último, la Ley Federal de Fomento de las Organizaciones de la Sociedad Civil, promulgada en el 2005, registra y regula a las Asociaciones y Sociedades Civiles que se dedican a la prestación de diversos servicios de Asesoría y Capacitación en diversas áreas de la actividad económica, social cultural y educativa. ${ }^{27}$

La presentación de los diferentes ordenamientos jurídicos que regulan las distintas figuras asociativas que forman parte del SSE permite advenir que las empresas sociales mantienen diferentes puntos de contacto entre sí, no existiendo una especialización funcional, territorial, social o económica claramente definida. No obstante, podemos considerar que el SSE en México se esta conformando con la participación de cuatro subsectores, a saber: agrario, cooperativo, de sociedades de solidaridad social y de agrupaciones de carácter civil.

En función de la situación normativa y legal que entregan tanto el ordenamiento constitucional, como los cuerpos legales que se han citado, se puede indicar que en la actualidad el sector de Economía Social (o el Sector Social de la Economía), está constituido especialmente por el siguiente tipo de entidades

a) Entidades del sector agrario, donde destacan los siguientes tipos de organizaciones:

- Ejidos

- Comunidades agrarias

— Uniones de Ejidos

- Sectores de producción

27 Rodrigàn Mario, ob. cit., p. 38. 
- Empresas especializadas

- Y otros tipos específicos de empresas rurales

b) Empresas cooperativas, donde tienen un peso muy superior todo el sistema de cooperativas de ahorro y crédito popular.

c) Sociedades de solidaridad social. Corresponden a sociedades de personas constituidos a lo menos por 15 personas tanto en el ámbito urbano como rural, que se orientan a práctica de la solidaridad social, la afirmación de valores cívicos, la independencia política del país, y a cualquiera actividad que ayude a elevar la calidad de vida de sus asociados.

d) Agrupaciones de la sociedad civil. Este tipo de agrupaciones tiene una larga data en México, a través de lo dispuesto en su Código Civil Federal, que cobra un nuevo impulso a través de la dictación en el año 2003 de la Ley Federal de Fomento de las Organizaciones de la Sociedad Civil. ${ }^{28}$

Los datos cuantitativos del sector de la Economía Social en México ò Sector Social, como quiere que sea su denominación, son los siguientes:

- Para el caso de las organizaciones asociativas agrarias, estas son en total para el segundo semestre de: 2008, 29.261 entidades, que asocian a un total de: 3,179816 personas.

- Para el caso del sector cooperativo éstas son un total de 13,316 empresas, que asocian a : 3,051281 personas.

— Las sociedades de Solidaridad Social son: 4371 organizaciones que agrupan a un total de: 143,187 personas.

- Las Asociaciones Civiles son 45, que asocian a un total de 7,881186 personas.

De ésta forma se observa que en Mèxico existen un total de 47,313 entidades propias de la Economía Social que asocian a un total de 7,881186 personas $^{29}$.

\section{Políticas Públicas de Economía Social en Mèxico}

En la mayoría de los estados democráticos la Economía Social ha sido fomentada a través de la entrega de recursos económicos y distintos programas de capacitación.

28 Ídem
29 Ob. cit., p. 58. 
Se presentan planes y proyectos para incentivar este tipo de organizaciones, así como la apertura de espacios para la negociación en conjunto, logrando posicionarse como una entidad consolidada dentro del mercado nacional y a veces en el internacional.

Sin embargo quienes han estudiado con profundidad a estos países, encuentran una gran divergencia entre el discurso oficial, estatal y los hechos esta es la puesta en marcha de acciones para las entidades de la ES, con lo cual se presume que todo queda en buenas intenciones.

En nuestro país se observa desde la Carta Constitucional, a la vez con la voluntad de los gobiernos locales que manifiestan la importancia de fomentar al sector social de la Economía, sin embargo lo que se refleja realmente son algunas lagunas legales y un desordenado esquema de ejecución, de las políticas públicas, lo cual impide alcanzar su consolidación. ${ }^{30}$

Por ejemplo; en la Constitución se menciona que :

...el Estado mexicano y los gobiernos que de el emanan tienen la obligación de dirigir y planear el desarrollo nacional, mediante el fomento económico de los sectores publico, social y privado, que favorecen el empleo y una mas justa distribución del ingreso y la riqueza, entre los individuos, grupos y clases que integran la nación...

Sin embargo como bien nos dice Rojas Herrera; actualmente ni desde el punto de vista jurídico ni de las políticas publicas, existe uniformidad o criterios comunes en lo relativo a la forma en que deben apoyarse o promoverse a las empresas y organizaciones que forman parte del sector social de la economía. ${ }^{31}$ (Rojas Herrera, 2006)

Lo anterior pone de manifiesto que no se estipula claramente que papel juegan las empresas sociales dentro de la economía nacional y por otra parte no existe el apoyo del estado que obligue a respetar un funcionamiento bajo los valores asociativos, en consecuencia se enfrenta un panorama desfavorable para la ES, que como bien comenta el citado autor:

lo cierto es que el contexto macroeconómico en el que las empresas nacionales deben mantener sus actividades asociativas y empresariales es bastante desfavorable, teniendo que enfrentar la apertura comercial indisciplinada, contrabando masivo de bienes y mercancías,

30 Ídem.

31 Rojas Herrera, J.J. (2006). «Análisis del panorama asociativo presente». Llamado Sector Social de la Economía Mexicana, en Pérez de Uralde J.M.: La Economía Social en Ibero América. Un acercamiento a su realidad, vol. 2 FUNDIBES, Valencia, pp. 113-153. 
ausencia de apoyo crediticio para financiar los procesos productivos y el retiro casi total de los apoyos gubernamentales a las actividades empresariales de las entidades asociativas del SSE ${ }^{32}$.

De tal suerte que se observa un diagnóstico sumamente pesimista para estas empresas por las políticas públicas de fomento y apoyo a la Economía Social, afirmando que no existe propiamente hablando una infraestructura institucional de apoyo al SSE ni un enfoque coherente en las políticas gubernamentales que privilegien el apoyo a este tipo de entidades asociativas, lo cual puede traducirse en un acceso limitado al financiamiento de sus actividades productivas, a una escasa capacitación y formación empresarial y por tanto una alta informalidad de sus actividades productivas.

De hecho se estipula que la intervención del estado realmente tiene un carácter paliativo para el SSE, además de desarticulado toda vez que no se observan directrices que generen una estrategia ordenada, sistemática y de largo plazo que realmente satisficiera los requerimientos mas elementales para el crecimiento y para el desarrollo de las unidades productivas del SSE en México.

En consecuencia puede afirmarse que hace falta poner en marcha políticas publicas que sean variables dentro del contexto en el que se desarrollan ya que como menciona el citado autor: "los representantes de las organizaciones sociales desean dejar de ser «población objeto» de programas oficiales cargados de asistencialismo y clientelismo y demandan la elaboración de verdaderas políticas públicas que favorezcan la asociatividad y el control de los recursos y los mercados por parte de los productores y consumidores locales». ${ }^{33}$

Por otra parte la Constitución General de la República como se ha mencionado plantea la necesidad de un desarrollo equitativo entre todos los sectores de la economía, reconociendo la existencia de un sistema donde confluyen tres actores principales, integrados por las organizaciones y empresas tanto del sector publico como privado y social.

Art. 25.

... al desarrollo económico nacional concurrirán, con responsabilidad social, el sector público, el sector social y el sector privado, sin menoscabo de otras formas de actividad económica que contribuyan al desarrollo de la nación...

32 Ídem.

33 Ob. cit., p. 67. 
Y continua diciendo el mencionado articulo:

...la ley establecerá los mecanismos que faciliten la organización y la expansión de la actividad económica del sector social: de los ejidos, organizaciones de trabajadores, cooperativas, comunidades, empresas que pertenezcan mayoritaria o exclusivamente a los trabajadores y, en general, de todas las formas de organización social para la producción, distribución y consumo de bienes y servicios socialmente necesarios...

Bajo estos conceptos de la Carta fundamental se derivan diversos ordenamientos jurídicos como hemos visto cuya finalidad es potenciar a la Economía Social, por ejemplo la Ley de Desarrollo Social (Enero 2004) cuyo objeto es fomentar al Sector Social de la Economía como lo demuestran los artículos 14 y 19 que mencionan:

...Son prioritarios y de interés público:

I. Los programas de educación obligatoria;

II. Las campañas de prevención y control de enfermedades transmisibles y los programas de atención médica;

III. Los programas dirigidos a las personas en condiciones de pobreza, marginación o en situación de vulnerabilidad;

IV. Los programas dirigidos a zonas de atención prioritaria;

V. Los programas y acciones públicas para asegurar la alimentación y nutrición materno-infantil;

VI. Los programas de abasto social de productos básicos;

VII. Los programas de vivienda;

VIII. Los programas y fondos públicos destinados a la generación y conservación del empleo, a las actividades productivas sociales y a las empresas del sector social de la economía...

Sin embargo y no obstante las buenas intenciones, no existe una clara conceptualización sobre que entidades quedan comprendidas dentro de este sector y cual será la definición del mismo.

Tampoco existe alusión a los valores y principios que la Economía social debiera considerar por lo que la ambigüedad de los mismos prevalece por sobre las buenas intenciones del aparato estatal.

Existen no obstante claros reclamos de diversos estudios sobre esta materia hacia el Poder Legislativo Federal para concretizar el tema de promoción y fomento de que habla la propia Constitución.

Se cuenta ya con diversos proyectos e iniciativas que pretenden reglamentar el artículo 25 Constitucional sin que hasta el momento se haya concretizado en algo. 


\section{El cooperativismo mexicano}

La Economía Social en México se ve reflejada de una manera muy importante a través del cooperativismo, no obstante que la historia de las cooperativas en nuestro país no siempre ha sido exitosa, puesto que hemos tenido avances y retrocesos y los casos exitosos que actualmente existen se relacionan con aquellas empresas que han tenido un comportamiento como empresa privada, con el consiguiente olvido de sus objetivos sociales o bien han tenido el apoyo gubernamental en forma de subsidios, o un mercado privilegiado o de alcance de cierta compatibilidad en áreas de servicios, con el sacrificio incluso de la auto retribución salarial por debajo de los mínimos de las demás empresas.

Por otra parte encontramos cierta confusión en la ley desde sus inicios, pues en efecto, fue en el Código de Comercio donde se promulgo por primera vez en el año de 1889 un apartado, en el que se contemplaba un breve capítulo referente a Sociedades Cooperativas, lo cual se ha venido considerado como el precursor de las instituciones cooperativas ${ }^{34}$.

Sin embargo los orígenes del cooperativismo en México se ubican en 1839, fecha en que se fundó en Orizaba Veracruz la primera caja de ahorros con las características de una sociedad cooperativa.

Sus fundadores fueron empleados y artesanos, inspirados en ideas de cooperación y ayuda mutua, que en un tiempo les fueron transmitidos por los socialistas utópicos franceses.

De tal suerte que todas estas ideas de cooperación y ayuda mutua tuvieron en nuestro país un efecto muy particular pues al ser defendidas por los socialistas utópicos franceses, así como por ideólogos anarquistas, vinieron a sustituir lo que en nuestra tradición existía en las comunidades indígenas con el trabajo colectivo y la propiedad comunal de las tierras en los famosos: "calpullis aztecas».

Posteriormente las instituciones de tipo cooperativo que surgieron en México, nacieron en medio de grandes luchas sociales y agitaciones populares en defensa de sus grandes ideales, identificándose desde sus inicios con los movimientos: campesino y obrero (1800 a 1903).

En base a lo anterior podemos afirmar que en nuestro país han existido diversas leyes de cooperativas que reflejan su momento histórico, pues como se ha mencionado el precursor legal de las empresas cooperativas lo fue el Código de Comercio de 1889-1890, en virtud de que en su capítulo VII les dedicó 22 preceptos y las consideró como so-

34 «Datos Históricos sobre el cooperativismo en México», Revista Mexicana del Trabajo, México, Quinta Época, 1972, tomo IX, p. 9. 
ciedades mercantiles confundiéndolas con la sociedad anónima, la cual podía construirse como empresa de responsabilidad limitada o ilimitada y no se les dio ningún tratamiento especial.

En el Código de Comercio las sociedades cooperativas fueron consideradas como una variante de las sociedades mercantiles y fueron definidas de esa manera, con todas sus características generales como fueron: el número de socios, el capital variable, su responsabilidad solidaria e ilimitada o limitada a una determinada suma menor igual o mayor que el capital social, etc. ${ }^{35}$.

Por lo anterior puede decirse que una de las grandes aportaciones que trajo consigo la Revolución Mexicana de 1910 fue que se estableció a través de la Constitución de 1917 en nuevo orden social y económico así como un nuevo Proyecto Nacional, consecuentemente al crearse las bases para un sector social de la economía se insertaron automáticamente las empresas cooperativas, delimitadas por los artículos: 28, 27, 31 F. IV; 73 F. VII y X; 123 y 131 Constitucionales.

Asimismo con la Revolución Mexicana se contempló el movimiento cooperativo con agrado de tal manera que se fomentó el desarrollo y protección al mismo; como consecuencia lógica del impulso que se pretendió dar a este movimiento surgió en el año de 1927 la primera Ley General de Sociedades Cooperativas, en el Diario Oficial el 23 de febrero de 1927, que a diferencia del Código de Comercio de 1889, propicia un ambiente legal y adecuado para las sociedades cooperativas.

La primera Ley General de Cooperativas fue promulgada el 10 de febrero de 1927 y estuvo referida a las sociedades cooperativas agrícolas, industriales y de consumo. Esta ley fue muy progresista al autorizar objetivos múltiples las cooperativas, sin embargo de vigencia breve, dadas las contradicciones existentes entre las disposiciones del texto legal y los fines mismos del cooperativismo.

Posteriormente a esta Ley y como consecuencia de las deficiencias que existían en su contenido , fue derogada por otra nueva ley; la de 1933 la cual trató de adecuarse más a las necesidades y a la realidad imperante en el momento de su nacimiento. En efecto con fecha 30 de Mayo de 1933 apareció en el Diario Oficial, este nuevo ordenamiento que intentó enmendar las deficiencias de la ley anterior, tratando de ajustarse a los postulados tradicionales de la ideología cooperativa, adoptando con ello algunos criterios de legislaciones extranjeras que enarbolaban todos estos principios.

35 Labriega Villanueva, Pedro Alfonso, La reforma de legislación Mercantil, México, Porrúa, 1985, p. 234. 
Se derogaron las disposiciones del Código de Comercio relativos a las sociedades cooperativas (que se encontraban vigentes con la ley anterior) y se les dotó de un reglamento que no se tenía con la antigua (D.O. 21. v. 1934).

Esta ley, había sido considerada a juicio de muchos como una «magnífica ley», y sin embargo en el año de 1938 (D.O. 15-II-1938) se promulgó una nueva Ley General de Sociedades Cooperativas; quedando derogada la ley anterior, así como su respectivo reglamento, No obstante lo anterior en la exposición de motivos se alude a su naturaleza especial.

De hecho puede decirse que el sexenio del Presidente Lázaro Cárdenas (1934-1940) fue el periodo de ascenso para el movimiento cooperativo mexicano, ya que el Gobierno Cardenista propició la constitución de cooperativas tanto en el campo como en la ciudad. Este programa respondía a una política de gran apoyo al cooperativismo que tuvo su máxima expresión en el plan sexenal, cuyas ideas iban tendientes a fortalecer el aparato estatal para convertirlo en un promotor del desarrollo económico y social.

El cooperativismo en ese entonces se concibió como un sistema apropiado para organizar empresas productivas y promover socialmente a contingentes de trabajadores bajo la idea de ampliar y fortalecer al movimiento cooperativo aún bajo el entrenamiento del capital extranjero, lo cual motivó al cardenismo para renovar al cooperativismo mexicano sobre bases más firmes, más populares y solidarias con los sectores obreros y campesinos.

Por lo anterior podemos afirmar que desde los años 30 el movimiento cooperativo mexicano ha estado ligado directamente a los avances y retrocesos que ha sufrido el movimiento popular.

Por otra parte puede afirmarse que fue hasta 1982 que se recibieron apoyos del Gobierno Federal, con el último «Plan Nacional de Fomento Cooperativo».

Posteriormente se fueron generando cambios y ajustes en la política económica y social, y bajo el arribo de Carlos Salinas de Gortari, los instrumentos financieros prácticamente desaparecieron, para la mayoría de las sociedades cooperativas.

Se produjo un cambio en el marco jurídico que regula a las empresas cooperativas con la «nueva» Ley General de Sociedades Cooperativas de 1994, en efecto la Ley que nos rige actualmente en materia cooperativa es la Ley General de Sociedades Cooperativas publicada el 3 de agosto de 1994; la cual trata de adecuar el contenido de su redacción a las necesidades impuestas en nuestra sociedad. Cabe señalar que existen otros ordenamientos jurídicos inclusive superiores a las 
leyes anteriormente citadas que regulan la existencia de él cooperativismo tal es el caso de nuestra Constitución Política de los Estados Unidos Mexicanos, Ley General de Sociedades Mercantiles; Ley Orgánica de la Administración Pública y Código Civil entre otros.

Durante el mes de junio de 1994. (Diario.Oficial .VI.1994), fecha en la que se emitió la nueva Ley General de Sociedades Cooperativas, en la exposición de motivos se menciona la necesidad de actualizar la ley de 1983 atendiendo al sector social de economía, haciéndose realizado 14 foros a nivel nacional, así como diversos estudios de la legislación cooperativa en otros países, que han destacado en su economía en base al sistema cooperativo, como es el caso de España, Francia, Italia, Alemania, Colombia, Israel, Inglaterra, Costa Rica, Panamá, Chile, entre otros ${ }^{36}$.

Entre las demandas de cambio se detectaron como de las más importantes:

a) Eliminación y control de vigilancia para el ejecutivo.

b) Acceso a los organismos jurisdiccionales a nivel local y regional, que puedan resolver de manera más ágil las controversias que se susciten.

c) La desconcentración del registro ejercida en cada estado incluso a nivel municipal.

d) Simplificación administrativa.

e) Necesidad imperiosa de capacitación tanto cooperativa como de aquellos aspectos que de alguna manera coincida con la materia.

f) Necesidad de facilitar un acuerdo desarrollo económico y comercial acceso al financiamiento.

h). Preservación de los principios y derechos de previsión social, y sobre todo una sólida organización que permita la integración cooperativa a nivel nacional.

En este orden de ideas la comisión de fomento cooperativo enfatiza sus objetivos de: actualización, regulación, simplificación de administración interna y se otorgaron opciones de crecimiento.

Con esta nueva ley no se requería la expedición posterior de un «reglamento» como sucede actualmente con las sociedades civiles y mercantiles, permitiendo que la no previsión por la propia ley lo determine cada sociedad más conveniente para su estructura productiva.

36 Véase exposición de motivos Ley General de Sociedades Cooperativas, 1994. 
Sin embargo, el comentario que se ha hecho a esta ley es que lejos de contener un auténtico espíritu cooperativista resultó ser una ley reguladora mas que de fomento y promoción al cooperativismo y si bien mostró algunos avances significativos como lo fue: la plena autonomía tanto en su constitución como en su funcionamiento, han existido escasos avances a partir de su promulgación por parte del movimiento cooperativista nacional, pues continúa estancado el crecimiento de estas empresas pese a las facilidades para su creación y registro ${ }^{37}$.

Ruíz de Chávez comenta al respecto que el proyecto de decreto que se presentó no fue de "fomento cooperativo» sino que fue simplemente de "sociedades cooperativas», cambiando con ello la esencia original para convertirlas en sociedades mercantiles, dejando drásticamente al movimiento cooperativo a su suerte sin siquiera una buena política, olvidando que para que las cooperativas puedan tener éxito los gobiernos deben crearles un entorno favorable para su crecimiento y desarrollo, siendo importante valorar la labor que realiza la Organización Internacional del Trabajo (OIT) y las Naciones Unidas (ONU) en concierto con la Alianza Cooperativa Internacional (ACI) sobre el establecimiento de los marcos de referencia de políticas que definan el papel del Estado en materia de cooperativas, dado que las ventajas que ofrecen las cooperativas, esta mejorando la vida de personas en todas partes ${ }^{38}$.

Como puede observarse la historia de las cooperativas en México ha sido difícil, el proyecto cooperativo en México se inserta dentro de una lucha de resistencia pero también de transformación, tanto de las condiciones actuales como de valores y modos de producción, sin embargo puede afirmarse que el cooperativismo debe tomarse como modelo para reconstruir el vinculo social que se ha perdido en el mercado, pero además existen otras razones por las que debemos seguir impulsando al cooperativismo mexicano como son entre otras:

- Por que el cooperativismo mexicano, forma una parte importante de la Economía Social.

- Por que contamos con las bases constitucionales y legales que nos permiten enfocar a un verdadero Constitucionalismo Social.

- Por que la historia de las cooperativas en México, va íntimamente ligada a la historia misma del país.

37 Ruiz de Chávez, Ausencia de fomento Cooperativo. http://www.imagenpolitica. com/editorialistas/m_ruizdc.html.

38 Idem. 
- Por que los principios de la Economía Solidaria, son los mismos que se plasman en la Ley General de Sociedades Cooperativas (art. 7 L.G.S.C.).

- Por que a la solidaridad, se le ha conocido en México desde que existían las organizaciones precortesianas como el Calpulli Azteca.

- Por que a pesar de todo, en México hemos contado siempre con un sinnúmero de cooperativas y de cooperativistas, casi siempre dejados a su suerte.

- Por que en la historia de nuestro país hubo una »época de oro» del cooperativismo mexicano que trajo consigo grandes logros y realizaciones productivas, bajo el gobierno de Lázaro Cárdenas

- Por que actualmente gran parte de la industria en el país (97\%), pertenece a la micro, pequeña y mediana empresa en donde se encuentran insertas las cooperativas mexicanas.

- Por que contamos con principios legales para reconocer en el campo la presencia del ejido.

- Por que a 14 años del Tratado de Libre Comercio hemos visto los resultados de una economía devastadora, feroz y excluyente que ha dejado a mas de la mitad de pobres en México, y una tercera parte en pobreza extrema.

- Por que nuestro país exige la necesidad de desarrollarse y responder a sus propias necesidades, integrando los valores de la solidaridad y la justicia social, a través de nuevos empleos y nuevas formas de organización.

Estas y muchas razones mas son las que nos orillan a considerar que:

OTRO MUNDO ES POSIBLE!*

\section{Bibliografía y fuentes}

CAdena Barquín, Félix. De la economía popular a la economía de solidaridad. Mèxico, 2005. El Colegio de Tlaxcala. FOMIX, ECOSOL, SEPUEDE.

CAStRo SAns, Marcos de, La Economía Social y solidaria, un proyecto complementario e incluyente, Foro Internacional de Economía Social y Solidaria (memoria), Secretaría de Economía, Comisión de Fomento Cooperativo y Economía Social, FONAES. México, 2002.

ChÀvez, Rafael y Monzón, José Luis. La Economía Social en la Unión Europea. Comité Económico y Social Europeo. 2009.

* México 2010. Bicentenario de la Independencia de México. 
Colomer Viadel, Antonio (coord.), Sociedad Solidaria y desarrollo alternativo, Madrid, Fondo de Cultura Económica, 1993.

Cooperativas En Centroamérica, IV Conferencia de la Federación de Universidades de América Central y Panamá, Guatemala, FUPAC Ediciones, 1979.

DelGado, Orlando, "Discurso y realidades», periódico La Jornada, 7 de Dic., 2001.

Flores Olea, Víctor, Crítica de la globalidad, México, Fondo de Cultura Económica. 2000.

Franco, J. La construcción del sector social, http//www.spin.com.mx/franco/ pobreza/social.html.

GineBRA, Joan, La Trampa Global, 2. ${ }^{a}$ reimp., México, Panorama, 1999.

Guerra Pablo, S., «Análisis socioeconómico de las economías alternativas», Revista Iberoamericana de Autogestión Comunal, Universidad de Valencia, España, núm. 34, Segunda Época, otoño 1999.

Labriega Villanueva, Pedro Alfonso, La reforma de legislación Mercantil, México, Porrúa, 1985.

LODGE, George C. Administrando la globalización en la era de la independencia, trad. de: Juan Carlos Jolly, México, Panorama, 1966.

RodrIGAN, Mario (coordinador), La Economía Social en Iberoamérica. FUNDIBES vol. 3, Valencia, 2008.

Rojas HerRera, Juan José. «Análisis del panorama asociativo presente». Llamado Sector Social de la Economía Mexicana, en Pérez de URALDE, J.M. (coordinador): La Economía Social en Ibero América. Un acercamiento a su realidad. FUNDIBES vol. 2 Valencia, 2006.

RuIz de ChÁvez, Mario. Ausencia de fomento cooperativo. En: http://www. imagenpolitica.com/editorialistas/m_ruizdc.html.

Stiglitz, Joseph E. El malestar de la globalización, Editorial Taurus, México, 2000.

Exposición de motivos de la Ley General de Sociedades Cooperativas. Congreso de la Unión 1994.

Comisión de fomento Cooperativo y Economía Social LVIII Legislatura de la Cámara de Diputados y Fondo Nacional de Empresas de solidaridad (FONAES), México, 2002.

Datos Históricos sobre el cooperativismo en México, Revista Mexicana del trabajo, México, Quinta Época, 1972, tomo IX. 